\title{
Pengaruh Transtibial Prosthesis terhadap Activity Of Daily Living Pasien Amputasi Bawah Lutut
}

\author{
Nur Rachmat ${ }^{1}$, M. Syafi' ${ }^{2 *}$ \\ ${ }^{1,2}$ Poltekkes Kemenkes Surakarta Jurusan Ortotik Prostetik \\ *Email: amfi86@gmail.com
}

\begin{abstract}
Background: The physical condition of patients with transtibial amputations affects the fulfillment of activity of daily living. Transtibial Prosthesis is used to increase the patient's activity abilities. This research is to find the effect of using transtibial prostheses on the activity of daily living. This study aims to determine the effect of the use of transtibial prostheses on the activities of daily life. Methods: This research method uses Quasi Experiment in the form of two-group post test only design. The study population was transtbial amputee at PT. Kuspito Prosthetic Orthotics. The sample in this study 40 people, namely 20 people using Transtibial Prosthesis, 20 people using Axial Crutches. The study was conducted at PT. Kuspito Prosthetic Orthotics from April to May 2019. This study used an observation sheet prepared by Kempen, et al (1996), namely The Groningen Activity Restriction Scale. Results: The normality test used is Shapiro Wilk. Mann Whitney test resuls shows an average difference of ADL between users of transtibial prosthesis users (22.40) and axillary crutch users (19.95) with a value = 0.008 where a $p$ value <0.05. Conclusion: So there is a difference in ADL which is statistically significant in patients using transtibial prosthesis and patients using axillary crutches. Where for transtibial prosthesis users better in ADL than axillary crutch users.
\end{abstract}

Keywords: transtibial prosthesis, activity of daily living, below knee amputee

\section{PENDAHULUAN}

Kemandirian untuk memilih sendiri hal yang ingin diputuskan untuk dirinya sendiri, tanpa harus menuruti pilihan orang lain (Husain, 2013). Kemandirian seserang didapatkan secara menyeluruh saat orang tesebut belajar dan berusaha mandiri menghadapi masalah dan mentukan sikapnya sendiri. Kemandirian yang dimiliki seseorang membuatnya dapat menentukan pilihan hidup untuk lebih (Husain, 2013).

Kemandirian dalam aktifitas seharihari dilakukan dengan mandiri melakukan kegiatan fungsional sehari (Ediawati, 2013). Kebutuhan seseorang berupa kesehatan dipengaruhi beberapa faktor yaitu berupa faktor keturunan, upaya untuk kesehatan perilaku sehat, dan lingkungan. Diperlukan dukungan dari tenaga kesehatan dan masyarakat untul meningkatkan pemenuhan kemandirian

\section{dalam aktiftas sehari-hari (Dai \& Adisaputra, 2019)}

Aktifitas sehari-hari pasien dipengaruhi oleh kemampuan pasien untuk memenuhi kecukupan kondisi fisik. Pasien yang mengalami amputasi mempunya masalah pada kekurangan pada fisiknya. Penanganan amputasi dapat diartikan dengan tindakan pembedahan yang membuang sebagian tubuh. Amputasi dilakukan mulai dari amputasi pada sebagian telapak kaki, amputasi separuh betis (transtibial amputation), amputasi pada sendi lutu (knee disarticulation), amputasi pada tulang paha (transfemoral) maupun amputasi pada pangkal paha (hip disarticulation). Amputasi transtibial adalah amputasi pada tulang betis atau tibia (Rachmat, 2016). Hilangnya sebagian anggota gerak pada tubuh manusia menyebabkan ketidak mampuan (disability) seseorang untuk 
melakukan aktivitas yang bervariatif. Beberapa faktor terjadinya kehilangan anggota gerak disebabkan seperti penyakit diabetes, cacat bawaan lahir, dan penanganan operasi (Amputasi) (Bacthiar et.al, 2014).

Individu pasca amputasi ekstremitas secara teknis mengalami kesulitan dalam melakukan gerakan yang kompleks dan taktil dan seringkali individu tersebut mengalami frustasi dan masalah-masalah lain dalam proses rehabilitasi (Jang et al., 2011). Pada amputasi transfemoral, penyesuaian diri dengan kehidupan pasca operasi merupakan hal yang tidak sederhana. Pasien amputasi transfemoral harus menghadapi berbagai masalah seperti peningkatan konsumsi energi ketika ambulasi, keseimbangan dan stabilitas, penggunaan prosthesis yang rumit, kesulitan untuk berdiri setelah duduk dan ketidaknyamanan ketika duduk (Berke et al., 2008). Karena kesulitan tersebut, pasien mengalami kekurangan pemenuhan aktifitas sehari - hari.

Pasien yang kehilangan kaki karena amputasi, menggunakan alat bantu prosthesis untuk membantu mengatasi keterbatasan-keterbatasan aktivitas. Pasien yang menggunakan prosthesis dapat terbantu dalam melakukan kegiatan sehariharinya. (Bacthiar et.al, 2014). Peran ortotik prostetik adalah memberikan layanan pembuatan alat ganti transfemoral prosthesis yang bertujuan untuk membantu mengembalikan fungsi anggota gerak tubuh yang hilang sehingga dapat meningkatkan kualitas kemandirian. Menurut Murray (2010) prosthesis dapat membantu mengatasi keterbatasanketerbatasan aktivitas yang terjadi pada seseorang yang kehilangan kaki akibat amputasi. Pasien yang menggunakan prosthesis diharapkan anggota gerak pasien dapat dilengkapi sehingga ia dapat menjalankan aktivitas sehari-hari.

Kahaduwa et al. (2009) berpendapat bahwa penggunaan kruk dapat digunakan untuk membantu ambulasi pada berbagai jenis disabilitas lokomotor. Dimana prinsip kerjanya adalah pemindahan tumpuan dari sisi yang mengalami disabilitas ke bagian aksila sehingga tujuan ambulasi pasien dapat terpenuhi. Berdasarkan survey yang dilakukan Laura G di Heather Mills Amputee Forum pada tahun 2004 didapatkan data $13,4 \%$ responden lebih memilih kruk untuk mendukung aktivitas sehari-hari mereka. Banyak responden memilih kruk dengan alasan lebih nyaman dan mudah digunakan, tidak menyebabkan nyeri pada stump, lebih efisien untuk ambulasi dan lebih ergonomis.

Penelitian ini bertujuan untuk mengetahui pengaruh penggunaan transtibial prosthesis terhadap activity of daily living.

\section{METODE PENELITIAN}

Sesuai dengan masalah yang diteliti, jenis eksperimen semu, untuk mengetahui penyebab dan akibat dari variable penelitian, dan mengurangi faktor perancu lain yang tidak diteliti. penelitian quasi eksperimen dengan desain two - group post test only. Penelitian dimulai dengan mengajukan permohonan ijin penelitian ke PT. Kuspito Ortotik Prostetik. Peneliti sudah mendapat ijin untuk melakukan penelitian, selanjutnya peneliti melakukan tahap pelaksanaan penelitian.

Penelitian ini menggunakan teknik total sampling maka seluruh populasi akan menjadi subyek penelitian. Peneliti menghubungi setiap subyek lalu menjelaskan jalannya penelitian dan manfaatnya, sampel yang setujui diminta menandatangani informed consent, lalu 
cara mengisi lembar observasi. Peneliti memberikan lembar observasi pada enumerator, dan mendampingi responden dalam melengkapi lembar observasi. Peneliti menggunakan 2 enumerator dalam pengambilan data observasi. Tahapan terakhir adalah tahap pengolahan dan interpretasi data. Peneliti mengumpulkan lembar observasi dilanjutkan mengolah data.

Penelitian dilaksanakan di PT. Kuspito Ortotik Prostetik pada bulan April-Mei 2019. Pemilihan lokasi penelitian tersebut didasarkan atas pertimbangan bahwa PT Kuspito Ortotik Prostetik merupakan klinik yang melayani pembuatan Prosthesis yang cukup terkenal di Indonesia. PT Kuspito Ortotik Prostetik melayani cukup banyak pasien yang sesuai dengan penelitian yang dilakukan. Populasi pada penelitian ini berjumlah 40 orang, dengan rincian pasien amputasi bawah lutut di PT. Kuspito Ortotik Prostetik.

Sampel yang diambil dengan metode total sampling, yaitu dengan melibatkan seluruh anggota populasi menjadi sampel. Penentuan metode ini karena populasinya sedikit dan spesifik, yaitu pasien transtibial amputasi. Total sampling diharapkan mendapatkan nilai yang lebih mendekati riil dan mengurangi penyimpangan nilai pada populasi (Usman \& Akbar, 2008). Sampel sebanyak 40 orang, yaitu 20 orang memakai Transtibial Prosthesis, dan 20 orang memakai Axial Kruk.

Penelitian ini menggunakan lembar observasi yang disusun Kempen, et al (1996) yaitu GARS (The Groningen Activity Restriction Scale). GARS (Kempen, et al., 1996) digunakan untuk mengidentifikasi keterbatasan pada kegiatan dasar dalam kehidupan seharihari (BADL) yang didalamnya termasuk mobilitas dan kegiatan instrumental dalam kehidupan sehari-hari (IADL). GARS menggeneralisasikan profil dari 2 skor domain dimasukkan pada item yang berjumlah yang sedikit, 18 item, yaitu terdiri dari 7 item domain IADL dan 11 item domain BADL. Ke-18 item tersebut selanjutnya dijumlah untuk menggambarkan skor total keterbatasan aktivitaas. Skor berkisar antara $18-72$ poin (Kempen, et al., 1996). Skala GARS memiliki validitas $(r=0,79)$, dan dalam penelitian terbaru diketahui Cronbach's alpha 0,95 yang merupakan hasil penelitian di Belanda, Prancis, Norwegia, Swedia dan Kanada.

\section{HASIL PENELITIAN}

Karakteristik subyek penelitian dibedakan menjadi dua berupa karakteristik subyek data kontinu yang meliputi usia dan ADL. Sedangkan untuk karakteristik subyek data kategorikal meliputi jeni kelamin, pendidikan, dan pekerjaan.

Statistik deskriptif karakteristik subyek penelitian data kontinu berdasarkan usia dan ADL pada kelompok pengguna transtibial prosthesis dan kelompok pengguna kruk aksila di tabel 1 . Hasil dari statistik deskriptif menunjukkan bahwa pada kelompok pengguna Transtibial Prosthesis, rata-rata usia subyek penelitian adalah 31,20 tahun yaitu termasuk dalam usia produktif dan ratarata ADL yaitu 22,40. Sedangkan pada kelompok kruk axila rata-rata usia subyek penelitian 27,95 tahun yang termasuk dalam kategori usia produktif dan rata-rata ADL adalah 19,95. 
Tabel 1. Karakteristik Subyek Data Kontinu

\begin{tabular}{lcclll}
\hline Variabel & n & Min. & Max. & Mean & Std.Dev \\
\hline Usia kelompok prosthesis & 20 & 20,00 & 44,00 & 31,20 & 7,08 \\
Usia kelompok Kruk & 20 & 15,00 & 45,00 & 27,95 & 7,39 \\
ADL kelompok Prosthesis & 20 & 18,00 & 26,00 & 22,40 & 2,74 \\
ADL kelompok kruk & 20 & 18,00 & 24,00 & 19,95 & 2,16 \\
\hline
\end{tabular}

Sumber : Data Primer 2019

Statistik deskriptif karakteristik kruk aksial sebanyak 18 subyek (90,0\%). subyek penelitian data kategorikal Kategori pendidikan mayoritas subyek berdasarkan jenis kelamin, pendidikan, penelitian mempunyai pendidikan SMA dan pekerjaan baik pada pengguna yaitu pada kelompok transtibial prosthesis transtibial prosthesis dan pengguna kruk aksila terlihat di Tabel 2

Hasil statistik deskriptif data kategorikal berdasarkan jenis kelamin mayoritas subyek penelitian adalah dengan jenis kelamin laki-laki yaitu pada kelompok transtibial prosthesis sebanyak 17 subyek $(85,0 \%)$ dan pada kelompok sebanyak 11 subyek $(55,0 \%)$ dan pada kelompok kruk aksial sebanyak 8 subyek $(40,0 \%)$. Kategori pekerjaan pada subyek penelitian yaitu pada kelompok transtibial prosthesis mayoritas memiliki profesi sebagai wiraswasta sebanyak 10 subyek $(50,0 \%)$ dan pada kelompok kruk aksial mayoritas subyek penelitian tidak bekerja sebanyak 10 subyek $(50,0 \%)$.

Tabel 2. Karakteristik Subyek Data Kategorikal

\begin{tabular}{lcccc}
\hline \multirow{2}{*}{ Jenis kelamin } & \multicolumn{2}{c}{ Transtibialprosthesis } & \multicolumn{2}{c}{ Kruk aksila } \\
\cline { 2 - 5 } & $\mathbf{n}$ & $\mathbf{\%}$ & $\mathbf{n}$ & $\mathbf{\%}$ \\
\hline Laki-laki & 17 & 85,0 & 18 & 90,0 \\
Perempuan & 3 & 15,0 & 2 & 10,0 \\
Jumlah & $\mathbf{2 0}$ & $\mathbf{1 0 0}$ & $\mathbf{2 0}$ & $\mathbf{1 0 0}$ \\
\hline Pendidikan & & & & \\
\hline SD & 1 & 5,0 & 3 & 15,0 \\
SMP & 3 & 15,0 & 5 & 25,0 \\
SMA & 11 & 55,0 & 8 & 40,0 \\
PT & 5 & 25,0 & 4 & 20,0 \\
Jumlah & $\mathbf{2 0}$ & $\mathbf{1 0 0}$ & $\mathbf{2 0}$ & $\mathbf{1 0 0}$ \\
\hline Pekerjaan & & & & \\
\hline Tidak bekerja & 1 & 5,0 & 10 & 50,0 \\
Swasta & 7 & 35,0 & 4 & 20,0 \\
Wiraswasta & 10 & 50,0 & 5 & 25,0 \\
Pelajar & 2 & 10,0 & 1 & 5,0 \\
Jumlah & $\mathbf{2 0}$ & $\mathbf{1 0 0}$ & $\mathbf{2 0}$ & $\mathbf{1 0 0}$ \\
\hline Sumber : & & &
\end{tabular}

Sumber : Data Primer, 2019

Normalitas data juga dilakukan. maka menggunakan statistik parametrik Apabila data terdistribusi normal $(p>0,05)$ yaitu Uji Independent Sample T-test. 
Apabila data terdistribusi tidak normal (p $<0,05)$ uji non parametrik yaitu uji Mann Whitney akan dipakai. Uji normalitas pada penelitian ini menggunakan Shapiro Wiljk yang digunakan untuk menguji ADL pada kedua kelompok dengan sampel kecil $(<$ 50) dapat dilihat di Tabel 3.

Tabel 3. Normalitas Data

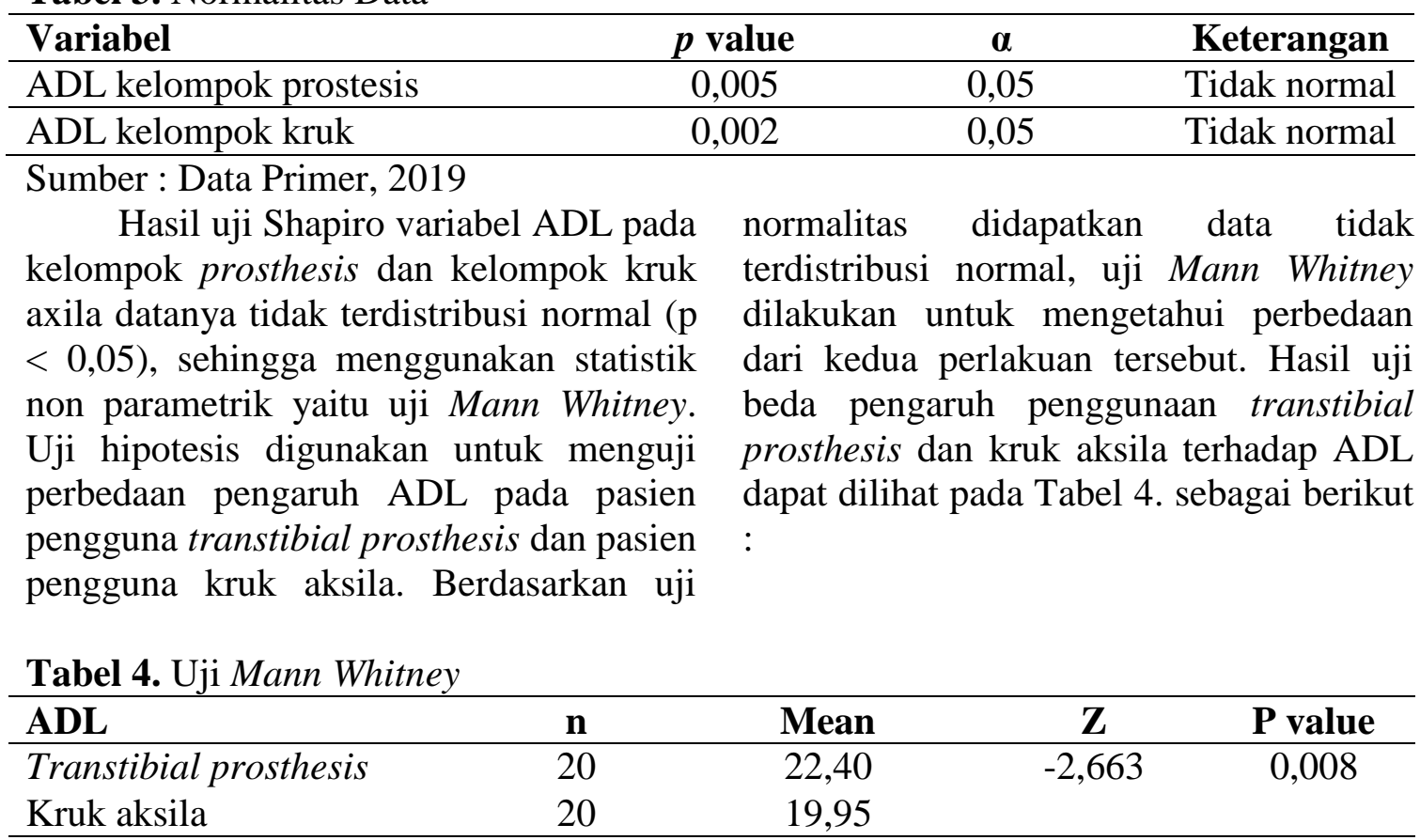

Sumber : Data Primer, 2019

Hasil uji Mann Whitney menunjukkan bahwa terdapat beda ratarata $\mathrm{ADL}$ antara pengguna pengguna transtibial prosthesis $(22,40)$ dan pengguna kruk aksila $(19,95)$ dengan nilai $\mathrm{p}$ value $=0,008$ dimana nilai $\mathrm{p}<0,05$ sehingga dapat disimpulkan terdapat perbedaan ADL yang secara statistik signifikan pada pasien pengguna transtibial prosthesis dan pasien pengguna kruk aksila. Dimana untuk pengguna transtibial prosthesis lebih baik dalam ADL daripada pengguna kruk aksila.

\section{PEMBAHASAN}

Hasil uji Mann Whitney menunjukkan bahwa terdapat beda ratarata ADL antara pengguna pengguna transtibial prosthesis $(22,40)$ dan pengguna kruk aksila $(19,95)$ dengan nilai $p$ value $=0,008$ yang mana nilai $p<0,05$ terdapat perbedaan ADL yang secara statistik signifikan pada pasien pengguna transtibial prosthesis dan pasien pengguna kruk aksila. Pengguna transtibial prosthesis lebih baik dalam ADL daripada pengguna kruk aksila. Hal ini berarti bahwa jenis transtibial prosthesis lebih fleksibel dan lebih nyaman digunakan untuk pemenuhan kegiatan sehari-hari sehingga dapat membuat pengguna lebih mudah dalam beraktivitas. Hasil penelitian ini didukung oleh penelitian dari Kachooei, et al (2014) bahwa terdapat hubungan penggunaan prosthesis dengan pemenuhan kebutuhan sehari-hari.

Penelitian pada beberapa orang pasca amputasai ekstremitas bawah 
menyimpulkan bahwa pasien pasca amputasi mengalami ketergantungan pada alat bantu dan memerlukan bantuan untuk memenuhi kebutuhan pribadi. Kemandirian untuk merawat diri sendiri telah digambarkan sebagai salah satu tujuan terpenting dalam proses rehabilitasi pasien pasca amputasi ekstremitas bawah (Zidarov et al., 2009). Selain itu, kemandirian pasien dalam melakukan ADL terutama aspek fisik ADL (PADL) juga berkaitan dengan tujuan tersebut. Penggunaan alat bantu berupa prosthesis (Bilodeau et al, 2000) diprediksi dapat meningkatkan kemampuan berjalan ke arah yang lebih baik (Sansam et al, 2009). Menurut National Council on Disability (2007) di USA, penggunaan prostesis pada pasien pasca amputasi dapat membantu ambulasi dan meningkatkan partisipasi dalam melakukan ADL secara mandiri. Hal ini diperkuat dengan pernyataan WHO (2001) bahwa penggunaan prostesis dapat memperbaiki persepsi medis, seperti peningkatan fungsi dan mobilitas, serta memperbaiki perspektif ICF yaitu meningkatkan aktivitas dan partisipasi dalam masyarakat.

\section{KESIMPULAN DAN SARAN}

Hasil penelitian mengenai
Perbedaan Transtibial Prosthesis terhadap Activity of Daily Living Pasien Amputasi Bawah Lutut, dapat disimpulkan bahwa terdapat beda rata-rata ADL antara pengguna pengguna transtibial prosthesis $(22,40)$ dan pengguna kruk aksila $(19,95)$ dengan nilai $p$ value $=0,008$ dimana nilai $p<0,05$ sehingga dapat disimpulkan terdapat perbedaan ADL yang secara statistik signifikan pada pasien pengguna transtibial prosthesis dan pasien pengguna kruk aksila. Penggunaan transtibial prosthesis lebih baik dalam ADL daripada pengguna kruk aksila.

Pasien yang mengalami amputasi bawah lutut disarankan untuk menggunakan transtibial prosthesis peningkatan aktivitas sehari - hari. Pasien yang belum memakai transtibial prosthesis sebaiknya memakai kruk agar tidak bisa beraktifitas.

\section{DAFTAR RUJUKAN}

Bachtiar, D., Audy, Jamari, Budiwn, I. (2014). Perancangan Biomekanisme Sendi Prostesa Untuk Pasien Amputasi Tungkai Atas Lutut dengan Desain Ergonomi dan Fleksibel, Prosiding SNST ke-5.

Berke, G.M., Buell, N.C., Fergasson J.R., Gailey, R.S., Hafner, B.J., Hubbard, S.M., Smith, D.G., Willingham, L.L. (2008). Transfemoral Amputation: The Basics and Beyond, Prosthetics Research Study, Kingston.

Bilodeau, S., Hebert, R., Desrosiers, J. (2000). Lower limb prosthesis utilisation byelderly amputees, Prosthet. Orthot. Int., 24 (2), $126 \mathrm{e} 132$.

Dai, N. F., \& Adisaputra, A. (2019). Hubungan Pengetahuan dan Sikap Perawat dengan Kebutuhan Pemenuhan Adl ( Activity Of Daily Living ) pada Usia Lanjut. 8, 46-51.

Ediawati, Eka. (2013). Gambaran Tingkat Kemandirian Dalam Actuvity Of Daily Living (ADL) Dan Resiko Jatuh Pada Lansia DI Panti Sosial Trsna Wredha Budi Mulia 01 dan 03 
Jakarta Timur. (Skripsi, Universitas Indonesia). Diunduh dari : digital_20314351- S43833Gambaran tingkat.pdf

Husain, Salindra. (2013). Hubungan Dukungan Keluarga Dengan Kemandirian Lansia Dalam Pemenuhan Aktivitas Sehari - hari Di Desa Tualango Kecamatan Tilango Kabupaten Gorontalo. (Skripsi, Universitas Negeri Gorontalo).

Jang, C.H., Yang, H.S., Yang, H.E., Lee, S.Y., Kwon, J.W., Yun, B.D., Choi, J.Y., Kim, S.N., Jeong, H.W. (2011). A Survey on Activities of Daily Living and Occupations of Upper Extremiy Amputees, Annals of Rehabilitation Medicine, Seoul.

Kachooei, A.R., Ebrahimzadeh, M.H., Hallaj-Moghadam, et al. (2014). Disabilities and Acvtivities of Daily Living Among Veterans With Old Hip Disarticulation and Transpelvic Amputation, Kashan University of Medical Sciences, Islamic Republic of Iran.

Kahaduwa, K.T.D., Weerasiriwardane, C.D.A., Wijeyaratne, S.M. (2009). A modified axillary crutch for lower limb amputees, University of Colombo, 2(1): 17-21.

Kempen, G.I.J.M., Miedema, I., Ormel, J., Molenaar, W. (1996). The Assessment of Disability Groningen Activity Restriction Scale. Conceprual Framework and Psychometric Properties, Elsevier Science Ltd., Great Britain.
Murray, C. (2010). Amputation, Prosthesis Use, and Phantom Limb Pain An Interdisciplinary Perspective, Springer Science Business Media, USA.

Rachmat, N., Syaifudin, M., Sulistyawati, P.U. (2016). Hubungan Panjang Stump Terhadap Kemampuan Lokomotor Pada Pasien Pengguna Transfemoral Prosthesis, Jurnal Poltekkes Solo, Surakarta.

Sansam, K., Neumann, V., O'Connor, R., Bhakta, B. (2009). Predicting walkingability following lower limb amputation: a systematic review of the literature, J. Rehabil. Med., 41 (8), 593e603.

World Health Organization. (2001). International classification of functioning, disability, and health, Geneva.

Zidarov, D., Swaine, B., Gauthier-Gagnon, C. (2009). Quality of life of persons withlower-limb amputation during rehabilitation and at 3-month followup, Arch. Phys. Med. Rehabil., 90 (4), 634e 